\title{
Mesomorphic behavior of methanesulfonate salts of esters of L-Methionine and their optical properties
}

\author{
SHEETAL VENKATESH, PUSHPA KUMARI YADAV and M M V RAMANA* (10 \\ Department of Chemistry, Lokmanya Tilak Bhavan, Vidyanagari, University of Mumbai, Kalina, Santacruz \\ (East), Mumbai 400 098, Maharashtra, India \\ E-mail: mmvramana@yahoo.co.in
}

MS received 18 February 2019; revised 2 May 2019; accepted 14 May 2019

\begin{abstract}
A set of methanesulfonate salts of esters of (S)-2-Amino-4-(methylthio)butanoic acid [LMethionine] and fatty alcohols have been synthesized in good yields by a green protocol involving a one-step and solvent-free approach. All derivatives have been evaluated for their liquid crystalline properties using polarizing optical microscopy and differential scanning calorimetry and found to be enantiotropic liquid crystals. Refractive indices were measured for one of the derivatives at different temperatures and wavelengths. It exhibited a high Abbe number and low dispersive power.
\end{abstract}

Keywords. Abbe number; dispersive power; enantiotropic; liquid crystals; refractive indices.

\section{Introduction}

Liquid crystals (LCs) are soft materials composed of self-organized molecules, capable of forming ordered and mobile states. ${ }^{1}$ At the phase transition from amorphous liquid to liquid crystalline state, the properties become anisotropic, which is an important feature of liquid crystals. ${ }^{2}$ LCs possess long-range orientational or positional ordering in at least one direction. The introduction of order into soft materials induces new dynamic functions. Liquid crystals are useful in low-power-consuming flat-panel displays which have allowed the development of mobile data processing and communication tools. ${ }^{3}$ They also find potential applications as new functional materials for electron, ion, or molecular transporting, sensory, catalytic, optical, and bioactive materials, sensing, catalysis, templates, and stimuli responsiveness as well as electro-optical displays. ${ }^{4}$

Ionic liquid crystals (ILCs) are a new class of compounds combining the properties of liquid crystals and ionic liquids. ${ }^{4}$ They are formed by a modification of the conventional design of liquid crystals by the introduction of ionic groups into them. ${ }^{5}$ ILCs are most-commonly built-up from long hydrophobic chains linked to a positively charged organic core and inorganic anions. This favors the formation of smectic structures by microphase segregation of the hydrophobic groups and charged groups. ${ }^{6}$ Another unique feature of ILCs is their spontaneous homeotropic alignment on a glass substrate. This spontaneous self-organization of the ionic mesophase is caused by interactions between cationic head groups and the surface and by an arrangement of hydrophobic tails, thus creating mono-domains of similarly oriented molecules of the ionic mesogens. ${ }^{7}$ ILCs have applications in directed synthesis, ${ }^{8}$ anisotropic tribology, ${ }^{9}$ ion self-assembly, ${ }^{10,11}$ molecular electronics, ${ }^{6}$ dye-sensitized solar cells, ${ }^{12}$ fuel cells ${ }^{13}$ and sensors. ${ }^{14}$

When compared with the huge library of liquid crystals, there are fewer number of ionic liquid crystals reported. Most of these liquid crystals are derived from heterocyclic cores. Largely popular ones are those derived from imidazolium cores. Some other examples include ionic liquid crystals based on guanidinium, pyrrolium, viologens, pyrazolium, triazolium, pyrrolidinium, etc. ${ }^{4,6,15}$ Their preparation methods involve multiple steps, use of expensive reactants, tedious purification steps and low yields. They are mostly nonbiodegradable, therefore, undergoing bioaccumulation and hence are not very eco-friendly.

\footnotetext{
*For correspondence

Electronic supplementary material: The online version of this article (https://doi.org/10.1007/s12039-019-1644-3) contains supplementary material, which is available to authorized users.
} 
In the present work, we report the preparation of ionic liquid crystals in good yields with the cationic part derived from an $\alpha$-amino acid, that is, (S)-2-amino4-(methylthio)butanoic acid [L-Methionine] esterified with fatty alcohols and the anionic part obtained from methane sulfonic acid. Amino acids and their derivatives are abundant sources of quaternary nitrogens and also readily available in pure form at low prices. Literature survey suggests that there are only a few reports ${ }^{16-19}$ of amino acids being used to make up the cationic part in ionic liquid crystals. Examples of ionic liquid crystals with protonated amino acid core are hardly known. This is the reason behind choosing an amino acid as the cationic part of this work. Attachment of a mesophase-inducing unit to other moieties is a common and effective strategy to induce LC behavior in a molecule. It helps in imparting the molecular assembly with shape anisotropy that is essential for liquid crystallinity. ${ }^{15}$ It is for this reason that fatty alcohols have been chosen as they help in inducing mesomorphism and at the same time provide shape anisotropy. The length of the alkyl chain influences the mesophases and melting points. The alkyl chain volume (i.e., the number and length of alkyl chains) influences the placement of the long alkyl chains (i.e., either all on the same side of the ionic planes, or on opposite sides of the ionic planes), as well as the degree of interdigitation between alkyl chains of neighboring molecules. ${ }^{15}$ Methane sulfonic acid has been chosen as the anion as anions with strong organic character have exhibited remarkable properties for thermal stabilities and reduction in the phase transition temperatures (PTTs). ${ }^{5}$ Another advantage is that all the three reactants involved: methane sulfonic acid, amino acid and fatty alcohols are easily available, inexpensive and biodegradable. ${ }^{20-22}$ The procedure employed for the synthesis comprises of a one-pot, solvent-free method with non-tedious workup, easy purification, high atomeconomy, high yields of the desired products and is in agreement with the principles of green chemistry. To the best of our knowledge, these are the first reports on the synthesis and refractive indices of ionic liquid crystals derived from L-Methionine.

\section{Experimental}

\subsection{Materials and methods}

All reactions were carried out in oven-dried glassware. Materials were obtained from commercial suppliers and used without further purification unless otherwise noted. Elemental Analysis was recorded on Euro Vector EUROEA 3000 Elemental Analyser. ${ }^{1} \mathrm{H}$ NMR $(300 \mathrm{MHz})$ and ${ }^{13} \mathrm{C}$ NMR
(75 MHz) spectra were recorded on Bruker AVANCE spectrometer (Bruker BioSpin AG, Fallanden, Switzerland; 300 $\mathrm{MHz}$ ) using $\mathrm{CDCl}_{3}$ or $\mathrm{MeOD}$ as a solvent. TMS was used as an internal standard. Infrared (IR) spectra were recorded on a Perkin Elmer (Model-Frontier) spectrometer (Waltham, MA, USA). Mass spectra were recorded on ABSCIEX 3200 QTRAP mass spectrometer. The phase transition temperatures and enthalpy values were measured by Mettler Toledo Differential Scanning Calorimeter at heating and cooling rates of $1{ }^{\circ} \mathrm{C} \mathrm{min}{ }^{-1}$, respectively. Transition temperatures were evaluated by Polarizing Optical Microscope using Mettler Toledo FP90 heating stage, containing temperature control unit in conjunction with a Carl Zeiss polarising optical microscope (Carl Zeiss MicroImaging GmbH, Koenigsallee, Goettingen, Germany). The mesophase type was assigned by visual comparison under the microscope with known phase standards. The samples studied by polarizing optical microscopy were prepared in thin films sandwiched between the glass slide and cover. The refractive indices were measured at various temperatures in the visible spectral region using a multiple wavelength Abbe Refractometer (DSR- $\lambda$ SCHMIDT + HAENSCH).

\subsection{Synthesis of $3 a-3 b$}

Compound $\mathbf{1}(0.149 \mathrm{~g}, 1 \mathrm{mmol})$ and fatty alcohols $\mathbf{2 a} / \mathbf{2 b}(1.1$ $\mathrm{mmol}$ ) were taken in a round bottom flask and heated to $120^{\circ} \mathrm{C}$ on a heating mantle equipped with stirring facility. The reaction mixture was stirred at this temperature for about $5 \mathrm{~min}$. To this reaction mixture, methane sulfonic acid $(0.115 \mathrm{~g}, 1.2$ mmol) was added in a dropwise manner over a period of 5 mins. The reaction was stirred at $130-135^{\circ} \mathrm{C}$ for 2 and $1 / 2$ $\mathrm{h}$ till the solution became golden brown. After completion of the reaction (as monitored by TLC), the hot golden brown solution was poured cautiously into $50 \mathrm{~mL}$ of chilled diethyl ether (dry ice-acetone bath). The resultant suspension was stirred for $2 \mathrm{~h}$ at room temperature and filtered to afford a buff coloured solid. It was purified by recrystallization from diethyl ether $(30 \mathrm{~mL})$ and dried in air to get pure product in good yields. The synthetic protocol for the preparation of $\mathbf{3 a} \mathbf{a} \mathbf{3 b}$ is outlined in Scheme 1.

(S)-4-(methylthio)-1-(octadecyloxy)-1-oxobutan-2-amin ium methane sulfonate (3a): as a white solid $(0.388 \mathrm{~g}, 78 \%)$; IR (neat) $\nu_{\max } / \mathrm{cm}^{-1}: 3418.22$ (br, N-H str.), 2915.21, 2848.53, 1745.31 (s, C=O str.), 1625.04 ( $\mathbf{N}-\mathbf{H}$ bending), 1538.94, 1470.10, 1333.43 (Asymm. S=O str.), 1204.26, 1147.83 (Symm. S=O str.), 1076.85, 776.49. ${ }^{1} \mathrm{H}-\mathrm{NMR}(300 \mathrm{MHz}$, $\mathrm{CDCl}_{3}, 25^{\circ} \mathrm{C}$, TMS) $\delta 8.097$ (s, $3 \mathrm{H},-\mathrm{CH}_{2}-\mathrm{CH}-\mathrm{NH}_{3}+$ ), 4.239 (t, $\left.J=6.9 \mathrm{~Hz}, 2 \mathrm{H},-\mathrm{CO}-\mathrm{OCH}_{2}-\right), 4.180(\mathrm{t}, J=6.9 \mathrm{~Hz}, 1 \mathrm{H}$, $-\mathrm{CH}_{2}-\mathrm{CH}-\mathrm{NH}_{3}+$ ), 2.775 (s, 3H, CH $3-\mathrm{SO}-$ ), 2.512 (t, $J=$ $\left.7.5 \mathrm{~Hz}, 2 \mathrm{H},-\mathrm{S}_{-} \mathrm{CH}_{2}-\mathrm{CH}_{2}-\right), 2.310-2.240(\mathrm{q}, J=6.9 \mathrm{~Hz}$, $2 \mathrm{H},-\mathrm{CH}_{2}-\mathrm{CH}-\mathrm{NH}_{3}+$ ), 2.114 (s, 3H, $\mathrm{CH}_{3}-\mathrm{S}_{-}-\mathrm{CH}_{2}-$ ), $1.683-$ $1.559\left(\mathrm{~m}, 2 \mathrm{H},-\mathrm{OCH}_{2}-\mathrm{CH}_{2}-\left(\mathrm{CH}_{2}\right)_{15}-\mathrm{CH}_{3}\right), 1.256(\mathrm{~m}, 30 \mathrm{H}$, $\left.-\mathrm{OCH}_{2}-\mathrm{CH}_{2}-\left(\mathrm{CH}_{2}\right)_{15}-\mathrm{CH}_{3}\right), 0.880$ (t, $J=6.9 \mathrm{~Hz}, 3 \mathrm{H}$, $\left.-\mathrm{OCH}_{2}-\mathrm{CH}_{2}-\left(\mathrm{CH}_{2}\right){ }_{15}-\mathrm{CH}_{3}\right) .{ }^{13} \mathrm{C}-\mathrm{NMR}\left(75 \mathrm{MHz}, \mathrm{CDCl}_{3}\right.$, $25^{\circ} \mathrm{C}$, TMS $) \delta 169.539(\mathbf{C}=\mathrm{O}), 66.748\left(-\mathrm{CO}-\mathrm{OCH}_{2}-\right), 52.034$ (-CH-NH$+\mathrm{N}_{3}+$ ), 39.288 ( $\left.\mathrm{CH}_{3}-\mathrm{SO}-\right), 31.945,31.783,29.737$, 
<smiles>CSCC[C@H](N)C(=O)O</smiles>

(S)-2-amino-4-(methylthio) butanoic acid [L-Methionine]

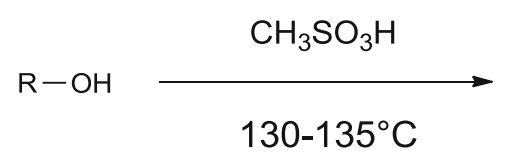<smiles>[R]OC(=O)[C@H]([NH3+])CCSC</smiles>

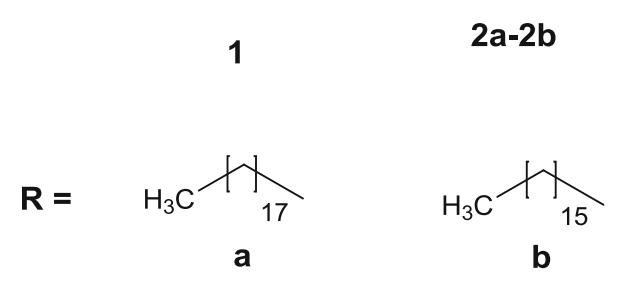

Scheme 1. General Scheme for the synthesis of compounds $\mathbf{3 a}$ and $\mathbf{3 b}$.

$29.574,29.382,29.284,25.834,22.704,15.032,14.120 . \mathrm{m} / \mathrm{z}$ calc. for $\mathrm{C}_{23} \mathrm{H}_{48} \mathrm{NO}_{2} \mathrm{~S}+\left[\mathrm{M}-\mathrm{CH}_{3} \mathrm{SO}_{3}^{-}\right]^{+}=402.700$, obs. mass $\left[\mathrm{M}-\mathrm{CH}_{3} \mathrm{SO}_{3}^{-}\right]^{+}=402.200,\left[(\mathrm{M}+\mathrm{H})-\mathrm{CH}_{3} \mathrm{SO}_{3}^{-}\right]^{+}=$ 403.300. Anal. calcd. for $\mathrm{C}_{24} \mathrm{H}_{51} \mathrm{NO}_{5} \mathrm{~S}_{2}$ (497.80): C, 57.91; H, 10.33; N, 2.81; S, 12.88; found: C 57.79, H 10.36, N, 2.82; S, 12.92 .

(S)-4-(methylthio)-1-(hexadecyloxy)-1-oxobutan-2-ami nium methane sulfonate (3b): as a white solid $(0.380 \mathrm{~g}$, $81 \%$ ); IR (neat) $\nu_{\max } / \mathrm{cm}^{-1}: 3423.36$ (br, N-H str.), 2952.83, 2914.78, 2847.94, 1745.88 (s, C=O str.), 1625.08 (N-H bending), 1470.85, 1379.87, 1318.09 (Asymm. S=O str.), 1205.63, 1147.24 (Symm. S=O str.), 1038.63, 775.02. ${ }^{1} \mathrm{H}-$ NMR (300MHz, MeOD, $\left.25^{\circ} \mathrm{C}, \mathrm{TMS}\right) \delta 4.252(\mathrm{t}, J=7.2 \mathrm{~Hz}$, $\left.2 \mathrm{H},-\mathrm{CO}-\mathrm{OCH}_{2}-\right), 4.143\left(\mathrm{t}, \mathrm{J}=6.6 \mathrm{~Hz}, 2 \mathrm{H},-\mathrm{CH}_{2}-\mathrm{CH}-\right.$ $\mathrm{NH}_{3}+$ ), 2.776 (s, 3H, CH$\left.{ }_{3}-\mathrm{SO}-\right), 2.675$ (t, $J=6.6 \mathrm{~Hz}$, $\left.3 \mathrm{H}, \mathrm{CH}_{3}-\mathrm{S}-\mathrm{CH}_{2}-\right), 2.543\left(\mathrm{t}, J=7.5 \mathrm{~Hz}, 2 \mathrm{H},-\mathrm{S}-\mathrm{CH}_{2}-\right.$ $\mathrm{CH}_{2}-$ ), 2.213-2.143 (q, $\mathrm{J}=7.2 \mathrm{~Hz}, 2 \mathrm{H}$; $-\mathrm{CH}_{2-} \mathrm{CH}_{2}-\mathrm{CH}-$ $\mathrm{NH}_{3}+$ ), $1.728-1.570\left(\mathrm{~m}, 4 \mathrm{H},-\mathrm{OCH}_{2}-\mathrm{CH}_{2}-\mathrm{CH}_{2}-\left(\mathrm{CH}_{2}\right)_{12}-\right.$ $\left.\mathrm{CH}_{3}\right), 1.269\left(\mathrm{~m}, 24 \mathrm{H},-\mathrm{OCH}_{2}-\mathrm{CH}_{2}-\mathrm{CH}_{2}-\left(\mathrm{CH}_{2}\right)_{12}-\mathrm{CH}_{3}\right)$, $0.863\left(\mathrm{t}, J=6.9 \mathrm{~Hz}, 3 \mathrm{H} ;-\mathrm{OCH}_{2}-\mathrm{CH}_{2}-\mathrm{CH}_{2}-\left(\mathrm{CH}_{2}\right)_{12}-\right.$ $\left.\mathrm{CH}_{3}\right) .{ }^{13} \mathrm{C}-\mathrm{NMR}\left(75 \mathrm{MHz}, \mathrm{MeOD}, 25{ }^{\circ} \mathrm{C}\right.$, TMS) $\delta 170.480$ $(\mathbf{C}=\mathrm{O}), 67.752\left(-\mathrm{CH}_{2}-\mathrm{CH}-\mathrm{NH}_{3}+\right), 52.853\left(-\mathrm{CO}-\mathrm{OCH}_{2}-\right)$, 39.589 ( $\left.\mathbf{C H}_{3}-\mathrm{SO}-\right)$, 33.108, 30.824, 30.722, 30.679, 30.510, $30.123,26.986,23.774,15.086,14.985,14.536 . \mathrm{m} / \mathrm{z}$ calc. for $\mathrm{C}_{21} \mathrm{H}_{44} \mathrm{NO}_{2} \mathrm{~S}^{+}\left[\mathrm{M}-\mathrm{CH}_{3} \mathrm{SO}_{3}^{-}\right]^{+}=374.40$ obs. mass [M$\left.\mathrm{CH}_{3} \mathrm{SO}_{3}^{-}\right]^{+}=374.300,\left[(\mathrm{M}+\mathrm{H})-\mathrm{CH}_{3} \mathrm{SO}_{3}^{-}\right]^{+}=375.200$. Anal. calcd. for $\mathrm{C}_{22} \mathrm{H}_{47} \mathrm{NO}_{5} \mathrm{~S}_{2}$ (469.74): C, 56.25; H, 10.08; N, 2.98; S, 13.65; found: C 56.09, H 10.11, N, 2.99; S, 13.69.

\section{Results and Discussion}

\subsection{Synthesis}

Esterification of L-Methionine with fatty alcohols [octadecan-1-ol (2a), hexadecan-1-ol (2b)] along with simultaneous salt formation using methane sulfonic acid yielded two derivatives: $\mathbf{3 a}$ and $\mathbf{3 b}$ in high yields and pure form. Detailed protocol for the synthesis of the derivatives can be found in the Experimental section. Both the derivatives were found to be solids and investigated for their liquid crystalline properties using Differential Scanning Calorimetry (DSC) and Polarizing Optical Microscopy (POM).

\subsection{Thermal and phase behaviour}

POM images were recorded at a scan rate of $1{ }^{\circ} \mathrm{C} / \mathrm{min}$ during heating and cooling. Identification of mesophases have been carried out by the comparison of the POM textures exhibited by the compounds (during heating and cooling cycles) with the reported ${ }^{23-25}$ textures. The compounds displayed Smectic C ( $\mathrm{SmC}$ ) phases during the heating and cooling cycles. Compound $\mathbf{3 a}$ displayed SmC phases during both heating and cooling, while compound $\mathbf{3 b}$ showed SmC phase during heating and Schlieren textures of SmC during cooling. Selected POM images of mesophases for the compounds $\mathbf{3 a}$ and 3b during heating and cooling cycles are displayed in Figure 1 and Figure 2.

The formation of the liquid crystalline phases was further confirmed by Differential Scanning Calorimetry (DSC) analysis of the synthesized derivatives. DSC analysis was carried out at a scan rate of $1{ }^{\circ} \mathrm{C} / \mathrm{min}$ during heating and cooling. Figure 3 shows the DSC thermograms of compound $\mathbf{3 a}$ and $\mathbf{3 b}$. Compound $\mathbf{3 a}$ showed transitions from crystalline solid to mesophase at $53.29{ }^{\circ} \mathrm{C}$. On cooling from the isotropic melt, a broad peak at $58.80{ }^{\circ} \mathrm{C}$ was observed corresponding to isotropic to liquid crystalline transition with an enthalpy change of $10.49 \mathrm{~kJ} / \mathrm{mol}$. Finally, a crystallization peak was observed at $46.50{ }^{\circ} \mathrm{C}$. Compound $\mathbf{3 b}$ exhibited 

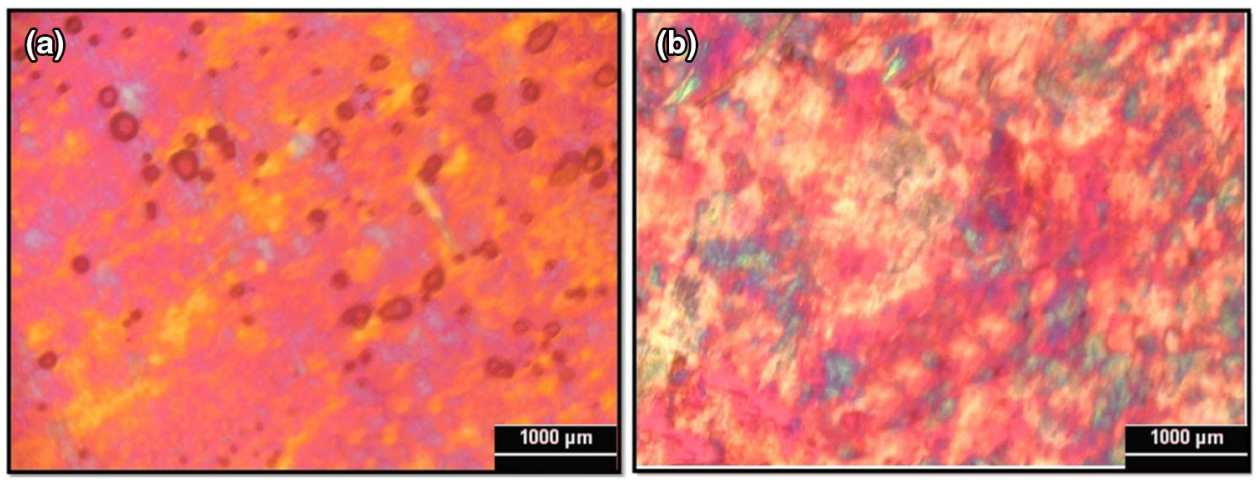

Figure 1. (a) Thermal optical micrograph of the SmC texture displayed by compound 3a during heating at $53.1^{\circ} \mathrm{C}$ at a scan rate of $1{ }^{\circ} \mathrm{C} / \mathrm{min}$ (magnification $=10 \mathrm{x}$; scale bar: $1000 \mu \mathrm{m})($ Magnification $=10 X$; Scale bar: $1000 \mu \mathrm{m})(\mathrm{b})$ Thermal optical micrograph of the $\mathrm{SmC}$ texture displayed by compound $\mathbf{3 b}$ during heating at $59.9{ }^{\circ} \mathrm{C}$ at a scan rate of $1{ }^{\circ} \mathrm{C} / \mathrm{min}$ (Magnification $=10 \mathrm{X}$; Scale bar: $1000 \mu \mathrm{m}$ ).
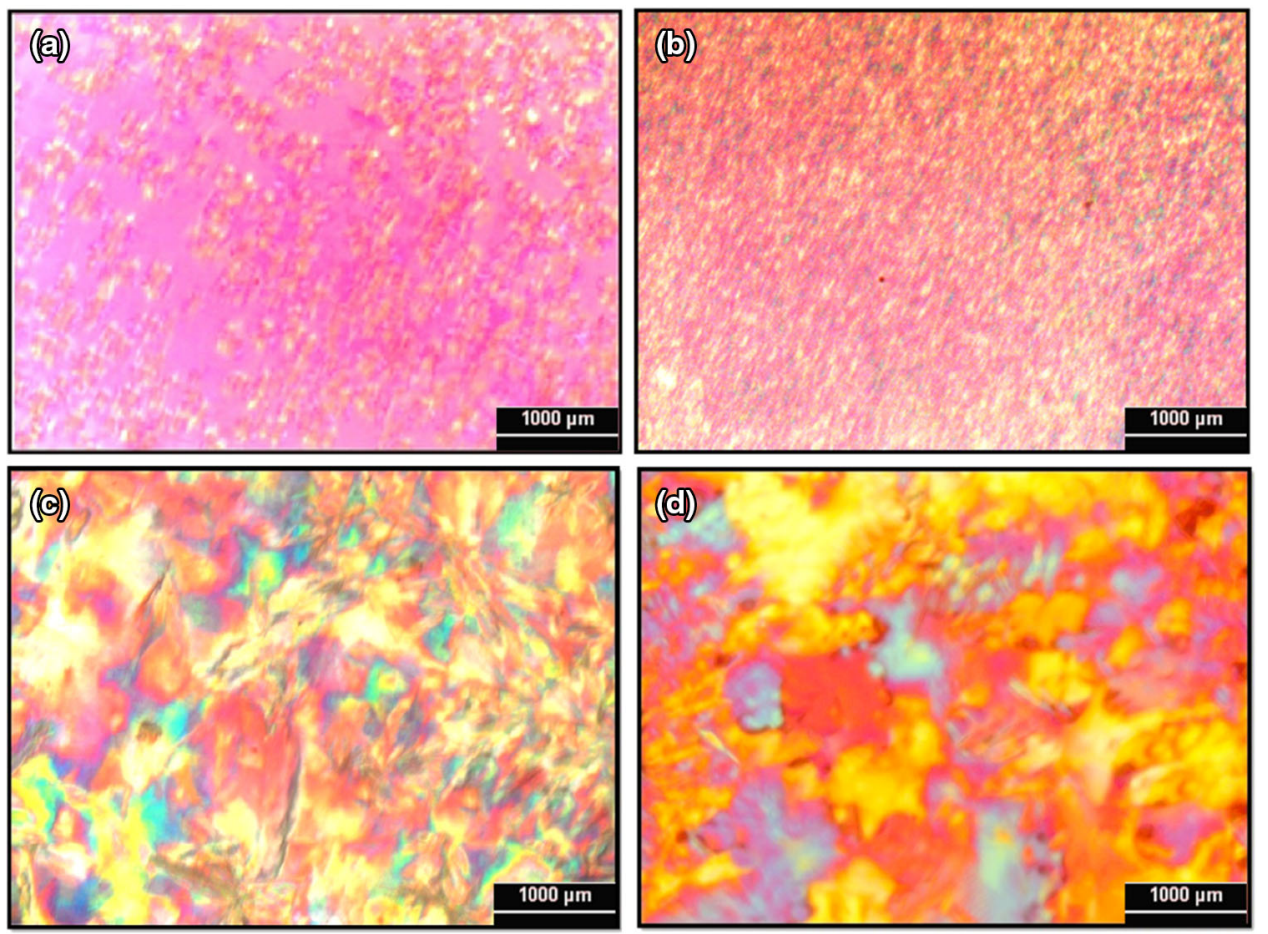

Figure 2. (a)-(b) Thermal optical micrograph of the SmC textures displayed by compound 3a during first and second cooling cycles at $58.6^{\circ} \mathrm{C}$ and $57.2^{\circ} \mathrm{C}$ at a scan rate of $1{ }^{\circ} \mathrm{C} / \mathrm{min}$ $($ magnification $=10 \mathrm{x}$; scale bar: $1000 \mu \mathrm{m})($ Magnification $=10 \mathrm{X}$; Scale bar: $1000 \mu \mathrm{m})$ (c)-(d) Thermal optical micrograph of the Schlieren textures of SmC phases displayed by compound $3 \mathrm{~b}$ during first and second cooling cycles at $74.5^{\circ} \mathrm{C}$ and $75.6^{\circ} \mathrm{C}$ at a scan rate of $1{ }^{\circ} \mathrm{C} / \mathrm{min}$ (Magnification $=10 \mathrm{X}$; Scale bar: $1000 \mu \mathrm{m}$ ).

two endothermic peaks at $62.32^{\circ} \mathrm{C}$ and $90.05{ }^{\circ} \mathrm{C}$, with the first peak corresponding to a transition from crystalline solid to liquid crystalline phase and the second peak corresponding to a transition from the mesophase to isotropic liquid. Two exothermic peaks at $74.83{ }^{\circ} \mathrm{C}$ and $73.42{ }^{\circ} \mathrm{C}$ were observed during the cooling process with enthalpy values of $0.29 \mathrm{~kJ} / \mathrm{mol}$ and 3.36 $\mathrm{kJ} / \mathrm{mol}$ respectively, with the first peak corresponding to a transition from the isotropic melt to liquid crystalline phase and the second peak corresponding to the transition from the mesophase to a crystalline solid (Table 1).

Compounds $\mathbf{3 a}$ and $\mathbf{3 b}$ were analyzed for their thermal stabilities using TG/DTA analysis at a scan rate of $10^{\circ} \mathrm{C} / \mathrm{min}$. Figure 4 shows the TG/DTA spectra of compound $\mathbf{3 a}$ and $\mathbf{3 b}$. 

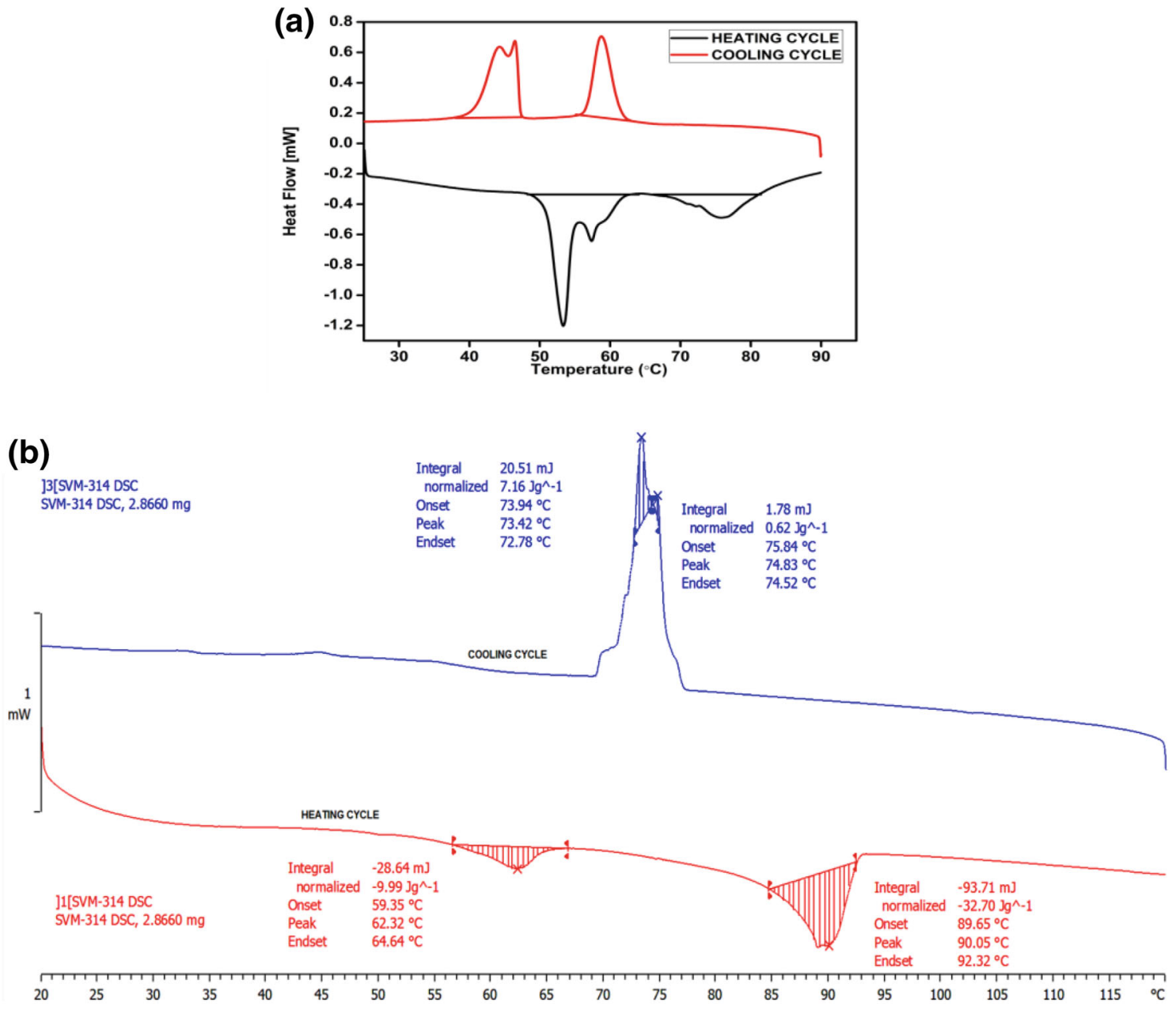

Figure 3. (a) DSC thermogram of compound 3a at a scan rate of $1^{\circ} \mathrm{C} / \mathrm{min}$ during heating and cooling (b) DSC thermogram of compound $\mathbf{3 b}$ at a scan rate of $1^{\circ} \mathrm{C} / \mathrm{min}$ during heating and cooling.

Table 1. The enthalpies $(\mathrm{kJ} / \mathrm{mol})$ and dimensionless entropies associated with the transition for compounds $\mathbf{3 a}-\mathbf{3 b}$.

\begin{tabular}{|c|c|c|c|c|c|c|c|}
\hline Entry & Compound & $\mathrm{R}-$ & \multicolumn{2}{|c|}{ Phase transitions $/{ }^{\circ} \mathrm{C}(\Delta \mathrm{H}$ in $\mathrm{kJ} / \mathrm{mol})$} & \multicolumn{2}{|c|}{$\Delta \mathrm{S} / \mathrm{R}$ (mesophase) } & Nature \\
\hline 1 & $\mathbf{3 a}$ & $\mathrm{C}_{18} \mathrm{H}_{35}$ & $\stackrel{53.29^{\circ} \mathrm{C}}{\longrightarrow} \mathrm{SmC}$ & $76.00^{\circ} \mathrm{C}$ & 4.5 & 3.80 & Mesomorphic \\
\hline & & & $\begin{array}{l}46.50^{\circ} \mathrm{C}(16.93) \\
62.32^{\circ} \mathrm{C}(4.69)\end{array}$ & $\begin{array}{l}58.80^{\circ} C(10.49) \\
90.05^{\circ} C(15.36)\end{array}$ & & & \\
\hline 2 & $3 \mathbf{b}$ & $\mathrm{C}_{16} \mathrm{H}_{31}$ & $C r \underset{73.42^{\circ} C(3.36)}{\rightleftharpoons} S m C$ & $74.83^{\circ} C(0.29)$ & 1.68 & 0.11 & Mesomorphic \\
\hline
\end{tabular}

Note: $\mathrm{Cr}=$ crystalline, $\mathrm{SmC}=$ smectic $\mathrm{C}$ phase, $\mathrm{I}=$ isotropic phase, $\delta \mathrm{H}=$ enthalpy change, $\delta \mathrm{S}=$ entropy change, $\mathrm{R}=$ gas constant $\left(8.314 \mathrm{~J} \mathrm{~mol}^{-1} \mathrm{~K}^{-1}\right)$.

From Figure 4, it can be seen that both the compounds showed no significant loss in weight between $40^{\circ} \mathrm{C}$ to $90^{\circ} \mathrm{C}$ which covers the melting point range of the compound. Decomposition was observed from $250{ }^{\circ} \mathrm{C}$ to $350{ }^{\circ} \mathrm{C}$.

\subsection{Study of refractive indices}

In case of a liquid crystalline compound, the polarized light encounters different refractive indices due to different polarizations of the incident light. Refractive indices are dependent on wavelengths and operating temperatures and are influential in optimizing the performance and device design of applications like thermally induced band-gap tuning, thermally tunable LC photonic crystal fibers, etc. ${ }^{26}$ They may increase or decrease according to the occurrence of reorientation of the LC molecules. Apart from molecular constituents, the most important parameters affecting the $\mathrm{LC}$ refractive indices are, wavelength and temperature. ${ }^{27,28}$ 

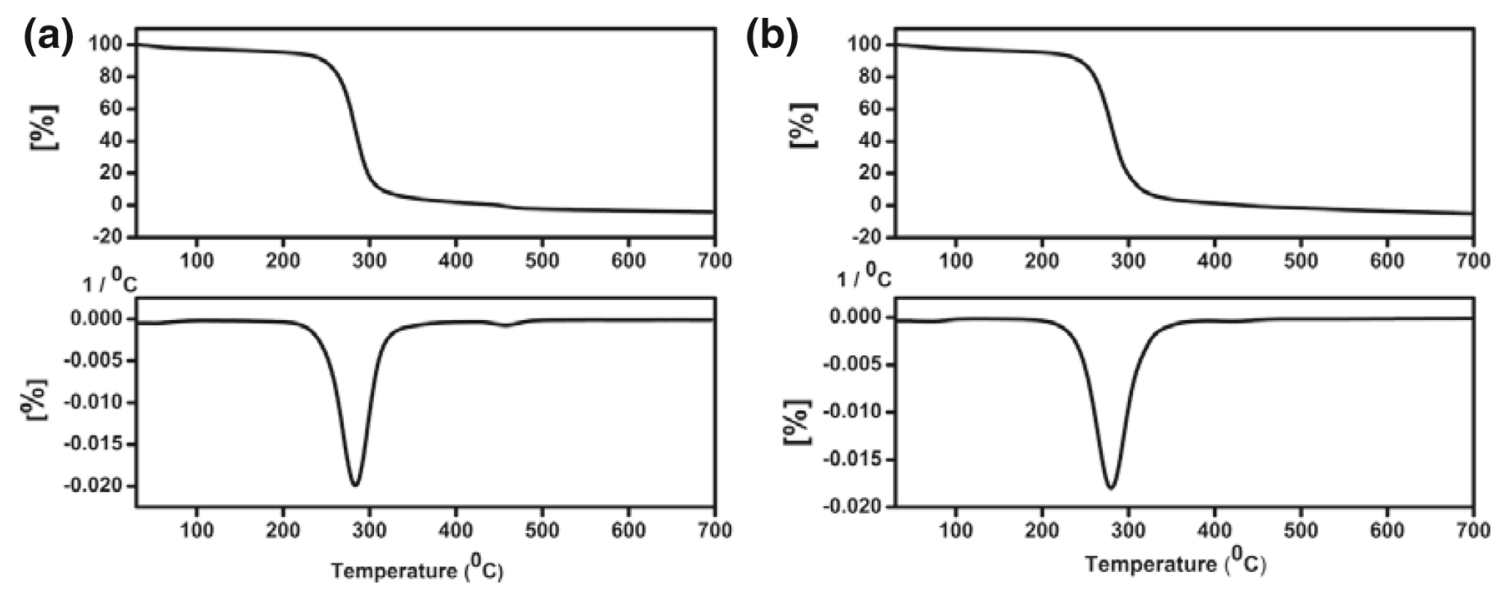

Figure 4. (a) TG / DTA of Compound 3a at a scan rate of $10^{\circ} \mathrm{C} / \mathrm{min}$ (b) TG/DTA of Compound $\mathbf{3 b}$ at a scan rate of $10^{\circ} \mathrm{C} / \mathrm{min}$.
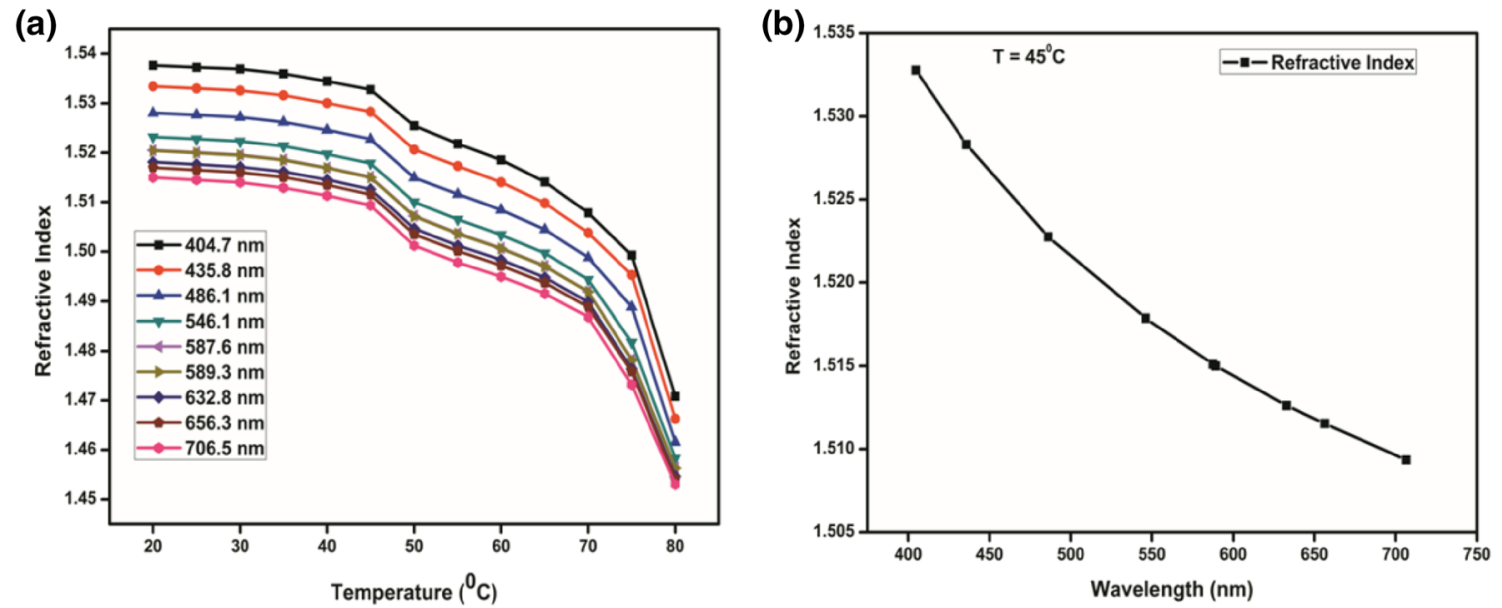

Figure 5. (a) Plot of Refractive Indices v/s Temperature at different wavelengths for Compound 3a (b) Plot of Refractive Indices v/s Wavelength at $45^{\circ} \mathrm{C}$ for Compound 3a.

The refractive indices of the liquid crystalline compounds are usually measured as a function of the operating temperatures and wavelength of the incident light. In this work, the refractive indices were measured in the visible region using a multiple wavelength Abbe Refractometer (DSR- $\lambda$ SCHMIDT + HAEN$\mathrm{SCH})$ for the wavelengths: $404.7,435.8,486.1,546.1$, $587.6,589.3,632.8,656.3$ and $706.5 \mathrm{~nm}$. The refractive indices were recorded by varying the temperature from $20{ }^{\circ} \mathrm{C}$ to $80{ }^{\circ} \mathrm{C}$ at an interval of $5{ }^{\circ} \mathrm{C}$ (Supplementary Information). The plots of Refractive Indices v/s Wavelength and Refractive Index $\mathbf{v} / \mathbf{s}$ Temperature for compound $\mathbf{3 a}$ are displayed in Figure 5.

This refractometer gives the average of both parallel and perpendicular refractive indices and hence, the refractive indices values are average of the two (equation 1). $\langle n\rangle=\left(n_{e}+2 n_{o}\right) / 3 \ldots \ldots \ldots$.

From Figure 5, it is clear that the refractive indices decrease with an increase in the temperature and wavelength. Thus, it can be noted that the refractive indices increase towards the blue region of the visible spectra as the wavelength decreases. A decline in the refractive indices can be observed in the range of $40-65{ }^{\circ} \mathrm{C}$ and this range corresponds to the range in which mesophases were observed during heating and cooling, which further confirms the existence of these intermediate liquid crystalline phases.

A term called 'Abbe number' was calculated for better characterization of this behavior. The equation to calculate Abbe number is given below (equation 2):

Abbe number $=\frac{n_{D}-1}{n_{F}-n_{C}} \ldots \ldots \ldots \ldots$ 
Table 2. Optical parameters calculated from the refractive indices data.

\begin{tabular}{lcc}
\hline Compound & Abbe number & Dispersive power \\
\hline $3 \mathrm{a}$ & 45.99 & 0.0217 \\
\hline
\end{tabular}

where,

$n_{D}$ is the index for sodium D line, that is, R.I. at 587.6

$\mathrm{nm}$

$n_{F}$ is the index for hydrogen $\mathrm{F}$ line, that is, R.I. at $486.1 \mathrm{~nm}$

$n_{C}$ is the index for hydrogen $\mathrm{C}$ line, that is, R.I. at $656.3 \mathrm{~nm}$

Abbe number is a quantitative measure of a material's dispersion, that is, the degree to which light is dispersed or separated when passing through a lens. When values of Abbe number are high, they indicate low dispersion. ${ }^{29}$ Abbe numbers are helpful while classifying optical materials like glass in terms of their chromicity. It can be noted that a material with high Abbe number produces less chromatic aberration than the one with a lower Abbe number. ${ }^{27}$ Higher values are indicative of better peripheral optics. Abbe numbers are important while designing achromatic lenses.

The reciprocal of Abbe number gives the Dispersive Power which is ${ }^{27,28}$ a measure of how much the colours making up of white light are spread out.

The Abbe number and Dispersive Power of compound 3a are tabulated in Table 2 .

Table 2 shows that the Abbe number value of compounds 3a is quite high and that the dispersive power low. This could be beneficial when it comes to their applications in optics design, tunable lasers, lens design, electrically tunable LC lenses, extra low dispersion glasses, etc. LC lenses exhibit large focal length tunability and low operating voltages. ${ }^{30}$ Unlike a mechanical zoom lens, the focal length of a LC lens can be tuned electrically. ${ }^{31}$ LC lenses have widespread applications in various fields like pico and holographic projection systems, endoscopic systems, ophthalmic lenses, etc. In imaging systems, LC lenses can help realize optical zoom and auto-focusing systems for portable devices like cellphones, camera, etc. ${ }^{32}$

\section{Conclusions}

Two methane sulfonate salt derivatives of esters of LMethionine have been successfully synthesized using biodegradable, inexpensive and readily available raw materials and in good yields by a green, one-step and neat procedure. Both the derivatives have been found to be enantiotropic liquid crystals. They showed mesophases below $100{ }^{\circ} \mathrm{C}$ during heating and cooling and thermally stablities upto a temperature of $250{ }^{\circ} \mathrm{C}$. The refractive indices have exhibited a decrease with an increase in the temperature and wavelength. A decline in the R. I. values in the range in which mesophases were observed during heating and cooling, confirms the existence of the liquid crystalline phases. The Abbe number value was found to be quite high and the dispersive power low, which is beneficial in applications like optical lenses, tunable lasers, electrically tunable LC lenses, extra low dispersion glasses, etc.

\section{Supplementary Information (SI)}

Supporting Information containing IR, ${ }^{1} \mathrm{H}-\mathrm{NMR},{ }^{13} \mathrm{C}-\mathrm{NMR}$ and Mass spectra of compounds $\mathbf{3 a}-\mathbf{3} \mathbf{b}$, DSC thermograms of compounds $\mathbf{3 a}-\mathbf{3} \mathbf{b}$, Refractive Indices data of compound 3a for this article is available at www.ias.ac.in/chemsci.

\section{Acknowledgements}

The authors thank the Department of Chemistry, University of Mumbai for financial support and facilities. Sheetal Venkatesh and Pushpa Kumari Yadav also thank UGC, New Delhi for the UGC Non-NET Ph. D Research fellowship.

\section{Compliance with ethical standards}

Conflict of interest There are no conflicts of interest to declare.

\section{References}

1. Kato T, Mizoshita N and Kishimoto K 2006 Functional liquid crystalline assemblies: self-organized soft materials Angew. Chem. Int. Ed. 4538

2. Pelzl G and Hauser A 1991 Birefringence and phase transitions in liquid crystals Phase Trans. 3733

3. Tschierske C 2013 Development of structural complexity by liquid-crystal self-assembly Angew. Chem. Int Ed. 528828

4. Binnemans K 2005 Ionic liquid crystals Chem. Rev. 105 4148

5. Paleos C M 1994 Thermotropic liquid crystals derived from amphiphilic mesogens Mol. Cryst. Liq. Cryst. 243 159

6. Kouwer P J and Fernandez A 2016 Key developments in ionic liquid crystals Int. J. Mol. Sci. 17731

7. Ujiie S and Iimura K 1992 Thermal properties and orientational behavior of a liquid crystalline-ion complex polymer Macromol. 253174

8. Do T D and Schmitzer A R 2015 Intramolecular Diels Alder reactions in highly organized imidazolium saltbased ionic liquid crystals RSC Adv. 5635 
9. Amann T, Dold C and Kailer A 2012 Rheological characterization of ionic liquids and ionic liquid crystals with promising tribological performance Soft Matter $\mathbf{8}$ 9840

10. Faul C J F 2014 Ionic Self-assembly for functional hierarchical nanostructured materials Acc. Chem. Res. 47 3428

11. Santella M, Amini F, Andreasen K B, Aswad D S, Ausar H, Austin, L M, Bora I, Boye I M I, Brinkenfeldt N K and Bøe M F 2015 Template-guided ionic self-assembled molecular materials and thin films with nanoscopic order Chem. Nano. Mat. 1253

12. Chi W S, Jeon H, Kim S J, Kim D J and Kim J H 2013 Ionic liquid crystals: synthesis, structure and applications to $\mathrm{I}_{2}$-free solid-state dye-sensitized solar cells Macromol. Res. 21315

13. Devaki S J and Sasi R 2017 Ionic liquids/ionic liquid crystals for safe and sustainable energy storage systems In Progress and Developments in Ionic liquids Scott Handy (Ed.) (UK: InTechOpen)

14. Woltman S J, Jay G D and Crawford G P 2007 Liquidcrystal materials find new order in biomedical applications Nat. Mater. 6929

15. Binnemans $\mathrm{K}$, Goossens $\mathrm{K}$, Lava $\mathrm{K}$ and Bielawsk $\mathrm{C}$ W 2016 Ionic liquid crystals: versatile materials Chem. Rev. 1164643

16. Echue G, Llyod-Jones G and Faul C F J 2015 Chiral perylene diimides: building blocks for ionic self-assembly Chem. Eur. J. 215118

17. Axenov K V and Laschat S 2011 Thermotropic ionic liquid crystals Materials 4206

18. Neidhardt M M, Wolfrum W, Breadsworth S, Wohrle T, Frey W, Baro A, Stubenrauch C, Giesselmann F and Laschat S 2016 Tyrosine-based ionic liquid crystals: switching from a smectic A Chem. Eur. J. 221

19. Neidhardt M, Schmitt K, Baro A, Schneider C, Bilitewski U and Laschat S 2018 Self-assembly and biological activities of ionic liquid crystals derived from aromatc amino acids Phys. Chem. Chem. Phys. 20 20371
20. Kulkarni P 2015 Methane sulphonic acid is green catalyst in organic synthesis Orient. J. Chem. 31447

21. Chen B, Fang J, Wu J, Huang W, Wang J and Zhang N 2013 The influence of amino acids on biodegradability, oxidation stability, and corrosiveness of lubricating oil J. Pet. Sci. Technol. 31185

22. UK/ICCA "SIDS Initial Assessment Profile" 2006 OECD Existing Chemicals Database

23. Yang M, Stappert K and Mudring A 2014 Bis-cationic ionic liquid crystals J. Mater. Chem. 2458

24. Govindaiah T N 2016 Electro-optical and thermodynamic studies on induced reentrant smectic-a phase in binary mixture of liquid crystalline materials Chem. Technol. Ind. J. 11106

25. Demus D and Richter L 1978 Textures of Liquid Crystals (Berlin: Verlag Chemie)

26. Li J 2005 Refractive Indices of Liquid Crystals and their Applications in Display and Photonic Devices Electronic Theses and Dissertations 4460

27. Jessy P J, Radha S and Patel N 2018 Morphological, optical and dielectric behavior of chiral nematic liquid crystal mixture: study on effect of different amount of chirality J. Mol. Liq. 255215

28. Jessy P J, Radha S and Patel N 2018 Highly improved dielectric behaviour of ferronematic nanocomposite for display application Liq. Cryst. 46772

29. Suzuki Y, Higashihara T, Ando S and Ueda M 2012 Synthesis and characterization of high refractive index and high Abbe's number poly(thioether sulfone)s based on Tricyclo [5.2.1.0 $0^{2,6}$ ]decane moiety Macromol. 45 3402

30. Ren H, Fox D W, Wu B and Wu S 2007 Liquid crystal lens with large focal length tunability and low operating voltage Optic Express 1511328

31. Lin Y, Wang Y and Reshetnyak V 2017 Liquid crystal lenses with tunable focal length Liq. Cryst. Rev. 5 111

32. Lin Y, Chen H and Chen M 2014 Electrically tunable liquid crystal lenses and applications Mol. Cryst. Liq. Cryst. 59612 